\title{
Exergetic Analysis of a Parabolic Trough Solar Collector Water Heater
}

\author{
Emmanuel Olayimika Sangotayo, Goodness Temitayo Opatola, \\ Azeez Abdulraheem, and Taiye Adeyemo
}

\begin{abstract}
Heat exchange mechanisms involved in the conversion of solar energy to heat were determined using a parabolic trough collector. This study's goal is to examine the impact of operational and environmental factors on the energetic, performance of three different Parabolic Trough Collector receivers used to generate hot water. The collectors used uncoated, grey, and black receiver tubes. The parabolic trough concentrator is built of mild steel as the mainframe support with a segmented mirror reflector. Reflectivity is $\mathbf{0 . 8 5}$, rim angle is 90, an aperture area is $2.42 \mathrm{~m}^{2}$, and concentration ratio is 11.7. The parabolic trough concentrator's focal point has galvanized iron receiving tubes. The receiver tubes were fitted individually via the parabolic reflector's focal point. The thermal exergy of each absorber tube was determined while water flowed at $0.003 \mathrm{~kg} / \mathrm{s}$. During the investigation, solar radiation, and water temperatures at the absorber tube's input and outflow were all measured. The results show that both the temperature of the heat transfer fluid and the amount of solar radiation have a substantial effect on thermal energetic performance. This concentrator reduces dependency on electric power while minimizing fossil-fuel emissions, reducing pollution.
\end{abstract}

Keywords - Concentrator, Exergy, Solar energy, Water heating.

\section{INTRODUCTION}

The Parabolic Trough Collector is the most mature and applied advanced technology in concentrated solar systems. Worldwide, this technology is being used to create and assess industrial processes as well as pure research [1]. The collector concentrates sunlight onto a solar heat exchanger (typically a vacuum absorber tube). A heat transfer fluid (HTF) is heated by a solar heat exchanger. A new generation of solar parabolic trough collectors can generate energy at temperatures up to $400{ }^{\circ} \mathrm{C}$ [2]. PTCs focus solar radiation onto a focal line and convert it into usable energy by heating a Heat Transfer Fluid (HTF). PTC performance is influenced by a mix of several operation factors in all-weather situations. An exergy analysis is proposed to estimate PTC performance in terms of work potential and exergy losses in terms of location, kind, and size. Most research has mostly focused on heat and electricity producing systems. Exergy analysis is used to find optimal operating settings or to evaluate system

Submitted on December 10, 2021

Published on January 18, 2022

Emmanuel Olayimika Sangotayo, Department of Mechanical Engineering, Ladoke Akintola University of Technology, Nigeria.

(e-mail: eosangotayo@lautech.edu.ng).

Goodness Temitayo Opatola, Department of Mechanical Engineering,

Ladoke Akintola University of Technology, Nigeria. performance, [3]. In some cases, the heat transfer fluid-power cycle coupling can be optimized [4], [5]. Exergy analysis has been used to cut fuel use in poly-generation units [6]-[8].

Exergy analysis has been employed in desalination processes that utilize PTC thermal solar power [9]; [10]. Optimum coupling between solar field PTCs and thermal desalination system is optimized in this scenario. Yahi1 et al. [11] determined the optical, and exergetic efficiencies of a parabolic trough solar collector using Matlab code. Exegetical efficiency increases with flow rate and increases with HTF inlet temperature. Carbon dioxide $\left(\mathrm{CO}_{2}\right)$, sulfur dioxide $\left(\mathrm{SO}_{2}\right)$, and nitrogen oxides $\left(\mathrm{NO}_{\mathrm{X}}\right)$ are released into the atmosphere when fossil fuels are burned to generate electricity. Experimental examination of the Parabolic Trough Solar Concentrator, PTSC Water Heater was conducted by Itabiyi et al. [13]. The maximum water temperature obtained from the PTSC water heater with a black-coated receiver was $70^{\circ} \mathrm{C}$ with a thermal efficiency of $8.1 \%$. The study showed that the solar concentrator as source of heat energy gives the best performance with the black receiver. Sangotayo et al. [14] evaluated the performance of a Parabolic Trough Solar Concentrator (PTSC) using copper, aluminum, and stainless steel receiver pipes. Copper receiver tubes transport heat to the heat transfer fluid more efficiently than aluminum and stainless steel receiver tubes. Sangotayo and Peter [15] conducted a comparative evaluation of the effect of thermo-physical properties on the performance of a parabolic trough solar collector. The findings revealed that water-based nanofluids significantly affect the thermal performance of the Parabolic Trough Solar Concentrator, PTSC. Heat transfer coefficient expanding by $20 \%, 21 \%$, and $14 \%$ using $\mathrm{TiO}_{2}, \mathrm{CuO}$ and $\mathrm{Al}_{2} \mathrm{O}_{3}$ respectively, as thermal conductivity increases by $23 \%$, and specific heat capacity reduce by $30 \%$.

A water heating system's parabolic trough solar concentrator has high efficiency, low cost and can be used to gather thermal energy or generate electricity. It is a costeffective use of solar energy, a renewable resource that is both clean and environmentally benign. The influence of absorber temperatures of the heat transfer fluid and climatic factors on the thermal exergetic performance of the PTC are presented in this analysis. The experimental exergetic analysis of galvanized iron receivers using a developed parabolic trough

Azeez Abdulraheem, Department of Mechanical Engineering, Ladoke Akintola University of Technology, Nigeria.

Taiye Adeyemo, Department of Mechanical Engineering, Ladoke Akintola University of Technology, Nigeria. 
collector system was carried out at the Department of Mechanical Engineering Workshop, Ladoke Akintola University of Technology Ogbomoso, Oyo State. The receiver temperature, ambient temperature, inlet, and output temperatures were monitored using a 12-channel temperature recorder, and the thermal exergetic efficiency at various parameters was studied.

\section{MEthodology AND MATERIALS}

\section{A. System Descriptions}

The Parabolic Trough Solar Concentrator (PTSC) has the following experimental characteristics: ease of construction, a strong and sturdy structure, lightweight, and low cost. The concentrator consists of a 27-segmented mirror measuring $(202 \mathrm{~cm} \times 5 \mathrm{~cm})$ that was maco-adhered to plywood. The segmented mirrors have been gummed together in the shape of a parabola. The segmented mirror was chosen because of its high reflectivity of 96 percent. The segmented mirror sheets are installed on the parabolic-shaped support framework.

The segmented mirror's size is proportional to the size of the supporting structure. The aperture's overall area is $2.424 \mathrm{~m}^{2}$, with a $90^{\circ}$ rim angle. The parabolic trough solar collector makes use of a segmented mirror in the shape of a parabolic cylinder to reflect and concentrate sunlight onto a receiving tube located at the parabolic cylinder's focus line. The receiver absorbs and converts incoming radiation to thermal energy, which is subsequently conveyed and collected by a heat transfer fluid medium that circulates inside the receiver tube. The receiver tube is constructed of galvanized iron tubes with black, grey, and uncoated reception tubes. The experimental setup for the constructed parabolic trough concentrator for domestic hot water use is depicted in Figure 1.0. A solar collector, a 10-liter storage tank, and a control valve that regulates the water flow rate compose the test setup. The data is measured and recorded using the test rig's associated measurement equipment. The relative humidity, temperatures and solar intensity were measured using the following devices: an SD Environmental meter, a 12 channel SD data logger temperature recorder, and a solar power meter.

\section{B. Construction of Parabolic Trough Solar Concentrator, PTSC}

The PTSC was constructed in an orderly fashion. The parabolic trough has both a receiver and a support structure. This section discusses each component in detail:

1. A Parabolic Trough is a trough with a parabola shape and plywood measuring, $202 \mathrm{~cm} \times 135 \mathrm{~cm}$ was used to construct the parabolic shape. Mechanical strength was added to the parabolic trough by the use of plywood. The segmented mirrors have been gummed together in a parabola shape. The reflector is constructed entirely of segmented mirrors attached to the plywood.

2. A galvanized iron absorber tube is located at the focal point of the parabolic trough. 2.21 meters in length, the galvanized iron has an internal diameter of 0.029 meters and an exterior diameter of 0.031 meters. Coated, uncoated, and grey receiver tubes were used to capture the solar energy reflected by the reflector more efficiently.

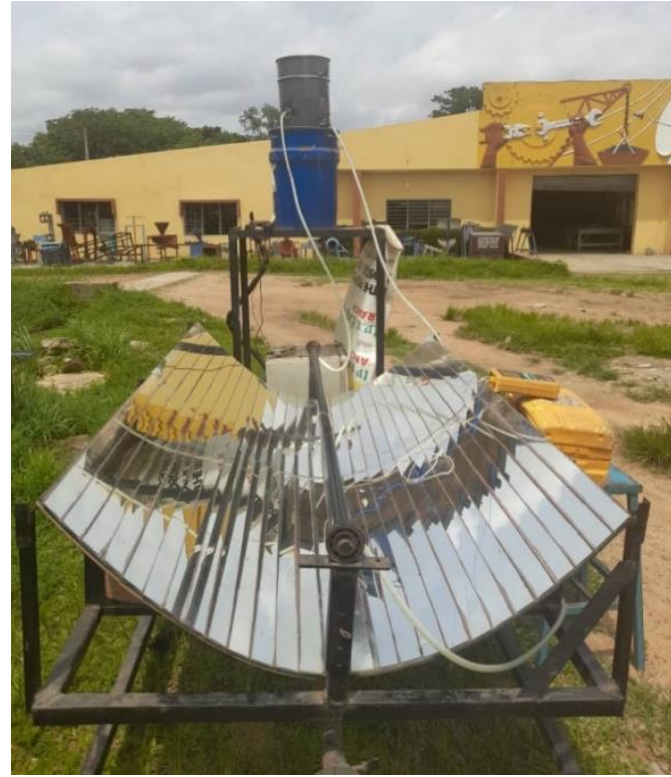

Fig. 1. The parabolic trough solar concentrator system with storage tank.

3. Support Structure: The supporting frame was designed in such a way that the collector's precision and stability are enhanced by placing the majority of the weight on the primary support structure. The frame was constructed in such a way that it can be easily dismantled and relocated.

The entire machine was mounted on a single frame, which made transporting it simple. Wheels were added to the frame to assist short-distance transportation, such as entering and exiting the laboratory for testing. A threaded strut was created to hold the mirror at any needed angle. It was necessary for proper alignment with the sun in any place.

4. Sun Tracking: Manual sun-tracking was performed throughout the testing phase. The system was oriented northsouth to collect the maximum amount of sunlight feasible. The collector was tracked to ensure that it was spinning eastwest. The horizontal axis was determined manually through observation of the sun's rays reflected off the reflective surface. The characteristics and dimensions of the terms utilized in the experiment are listed in Table I.

\begin{tabular}{ccc}
\multicolumn{2}{c}{ TABLE I: DIMENSION OF THE COLLECTOR } \\
\hline Item & Symbol & $\begin{array}{c}\text { Black, Grey } \\
\text { Uncoated, (GI) }\end{array}$ \\
\hline Rim Angle & $(\phi \mathrm{r})$ & $90^{0}$ \\
Focal Length & $(\mathrm{f})$ & $0.3 \mathrm{~m}$ \\
Aperture width & $\left(\mathrm{W}_{\mathrm{a}}\right)$ & $1.20 \mathrm{~m}$ \\
The outer diameter of the GI tube & $\left(\mathrm{D}_{\mathrm{o}}\right)$ & $0.031 \mathrm{~m}$ \\
The inner diameter of the GI tube & $\left(\mathrm{D}_{\mathrm{I}}\right.$ & $0.029 \mathrm{~m}$ \\
Length of the cylindrical trough & $(\mathrm{L})$ & $2.1 \mathrm{~m}$ \\
Effective Aperture Area & $\left(\mathrm{A}_{\mathrm{a}}\right)$ & $2.42 \mathrm{~m}^{2}$ \\
Concentration Ratio & $(\mathrm{C})$ & 11.7 \\
Reflectivity of the collector & $(\rho)$ & 0.63 \\
Absorptivity of the GI tube & $(\alpha)$ & 0.45 \\
Transitivity of the GI tube & $(\tau)$ & 0.8 \\
Intercept factor & $(\Upsilon)$ & 0.92 \\
\hline
\end{tabular}

\section{Experimental Setup and Procedure}

Experiments were conducted with a newly constructed parabolic trough collector system as a source of heat to heat receivers. Three unique galvanized iron receivers were used: one was black coated, one was gray coated, and one was bare. A parabolic trough collector was evaluated using three different galvanized pipe receivers, a ten-liter storage tank, a 
2.1-meter-long receiver's pipe, and a segmented mirror neatly gummed to maco and mounted on plywood to form the parabola shape. The water supply tank is elevated above the receiver's pipe level, which allows for the natural circulation of the heating fluid without the use of a pump. The storage tank was filled with water of 10 liter.

The experiment began with a system flush. After filling the system with water, the system was tested for the correct operation of all measuring instruments. The receiver of the parabolic trough collector is filled with cold water from the storage tank. The tank was placed above the collector's level to ensure a natural flow of water. Warm water flows spontaneously to the top of the water tank and is replaced by cold water from the bottom as solar energy heats the water in the receiver tube located at the trough's focal axis. When water is heated as it rises to the collector, the density of the water decreases, and the lighter-density water rises to the top of the storage tank to be stored. Water with a higher density enters the parabolic trough at the bottom of the tank, heats up, and rises to the top of the storage tank to be stored.

The water input and outlet temperatures of the receiver tube, the ambient and reflector temperatures, the receiver's surface temperature, solar radiation intensity, and relative humidity were all continuously measured during the experimental period of 9.00 am to $4.00 \mathrm{pm}$. A 12-channel temperature recorder equipped with thermocouples was used to measure the ambient, reflector, receiver outlet, and inlet temperatures of the system. A solar radiation meter was used to determine the intensity of the radiation, while an Environmental meter was used to determine the wind speed and relative humidity. Measurements were taken every five minutes during the experimental period.

The PTSC system's performance was evaluated using data from one of the classical days. The changes in ambient, reflector, outlet and intake temperatures were measured simultaneously using a K-type thermocouple connected to a temperature recorder located at various locations along the trough. The data were obtained at a mass flow rate of $0.003 \mathrm{~m}^{3} / \mathrm{s}$ to determine the concentrator's performance parameters for three galvanized iron tubes with black, grey, and uncoated receiver tubes. During the experiment, a cylindrical parabolic collector was oriented north-south (N$\mathrm{S}$ ) in the Department of Mechanical Engineering Workshop LAUTECH Ogbomoso.

\section{Thermal Performance Evaluations}

The performance analysis's objective is to offer an energetic description of the solar field under various operating conditions for the system under examination, such as solar radiation, ambient temperature, and wind speed.

The solar field's energetic efficiency and useable heat generation were used as performance parameters. Equation (1) can be used to determine the usable energy provided by the concentrator [12]

$Q_{u}=\dot{m} c_{p}\left(T_{o}-T_{i n}\right)$

where, $\mathrm{Q}_{\mathrm{u}}$ is the useful energy delivered from the concentrator (W); $m$, the mass flow rate of $0.003 \mathrm{~kg} / \mathrm{s} ; \mathrm{T}_{\mathrm{o}}$, outlet fluid temperature $\left({ }^{\circ} \mathrm{C}\right) ; \mathrm{T}_{\mathrm{in}}$, inlet fluid temperature $\left({ }^{\circ} \mathrm{C}\right) ; \mathrm{C}_{\mathrm{p}}$, specific heat of water $\left(\mathrm{kJ} / \mathrm{kg}^{\circ} \mathrm{C}\right)$.

The useful energy gain per unit of the collector length can be expressed using (2):

$Q_{u}{ }^{1}=\frac{m c_{p}\left(T_{o}-T_{i n}\right)}{L}$

\section{1) Optical Exergy Rate}

Not all solar energy reaches the receiver due to the optical qualities of the materials involved (e.g., the reflectance of the dish and the optical properties of the receiver).

As a result, the optical exergy rate is calculated as follows:

$\mathrm{E}_{\mathrm{opt}}=\left(1-\eta_{o}\right) I_{b} A_{a} \eta_{p}$

where, $\mathrm{E}_{\mathrm{opt}}$ is the optical exergy rate, $\eta_{o}$ is the optical efficiency, $\eta_{p}$ is the Petela's efficiency, $I_{b}$ is the global irradiance, $A_{a}$ is the aperture area.

$\eta_{p}=\frac{1-4 T_{a}}{3 T_{S}}+\frac{1}{3}\left(\frac{T_{a}}{T_{s}}\right)^{4}$

$\eta_{o}=\rho(\tau \alpha) \Upsilon$

\section{2) Thermal Efficiency}

For solar collectors in general, the collector overall efficiency $\eta_{c}$ is defined as the ratio between the useful output $Q_{u}[\mathrm{~W}]$ delivered by the collector to the global irradiance I $\left[\mathrm{W} / \mathrm{m}^{2}\right]$ incident on the collector aperture area $A_{a}\left[\mathrm{~m}^{2}\right]$.

$\eta_{c}=\frac{Q_{u}}{Q_{s}}$

For a concentrating collector, the useful output $Q_{u}$ can be expressed as:

$\mathrm{Qu}=\mathrm{m} \cdot \mathrm{Cp} \cdot\left(T_{O}-T_{i}\right)$

$=A_{a} \cdot I_{b} \cdot \eta_{o}-A_{a b s} \cdot U_{i} \cdot\left(T_{a b s}-T_{a}\right)$

where, $\mathrm{m}$ is the mass flow rate, $\mathrm{Cp}$ is the specific heat capacity, $T_{O}$ is the outlet temperature, $T_{i}$ is the inlet temperature.

$Q_{s}=A_{a} \cdot I_{b}$

\section{3) Exergy Efficiency}

Exergy Efficiency is the value assigned to the ratio of total exergy output to total exergy input as given in (9):

$$
\text { Exergy Efficiency }=\frac{E_{\text {gain }}}{E_{I N}}
$$

$E_{\text {gain }}=\mathrm{m} C_{p}\left(T_{2}-T_{5} \ln \frac{T_{2}}{T_{5}}\right)-\mathrm{m} C_{p}\left(T_{1}-T_{5} \ln \frac{T_{1}}{T_{2}}\right)$

$E_{I N}=\mathrm{m} C_{p}\left(T_{1}-T_{5}-T_{5} \ln \frac{T_{2}}{T_{5}}\right)$

where $\mathrm{m}$ is the mass flow rate, $\mathrm{Cp}$ is the specific heat capacity, $T_{2}$ is the outlet temperature, $T_{1}$ is the inlet temperature, $T_{5}$ is the ambient temperature 


\section{4) Useful Energy}

Useful Energy can be determined using (12):

$Q_{S}=\mathrm{mC}_{p}\left(T_{2}-T_{1}\right)$

\section{5) Heat Loss}

Heat loss, HL can be expressed using (13):

$\mathrm{HL}=Q_{S}-Q_{U}$

\section{RESULTS AND DISCUSSIONS}

Numerous observations on the PTSC system were made at the campus of Ladoke Akintola University of Technology, Ogbomoso. A set-up is located at Latitude $8.1227^{\circ} \mathrm{N}$, Longitude $4.2436^{\circ} \mathrm{E}$, and Elevation $347 \mathrm{~m}$. The graphs in Fig. 2-8 illustrate data on various days.

Testing began at 9:00 a.m. local time. Water was injected into the receiver tube five minutes before the actual reading. The temperature of the water was checked and recorded every five minutes and ensure that the incoming beam radiation is always normal to the reflecting surface.

The solar intensity profile on a sunny day is depicted in Fig. 2. The greatest sun intensity reported for the uncoated receiving tube was $300 \mathrm{~W} / \mathrm{m}^{2}$ and occurred between $12: 56 \mathrm{pm}$ and 1:11 pm this day. It indicates dynamics nature of environmental factors

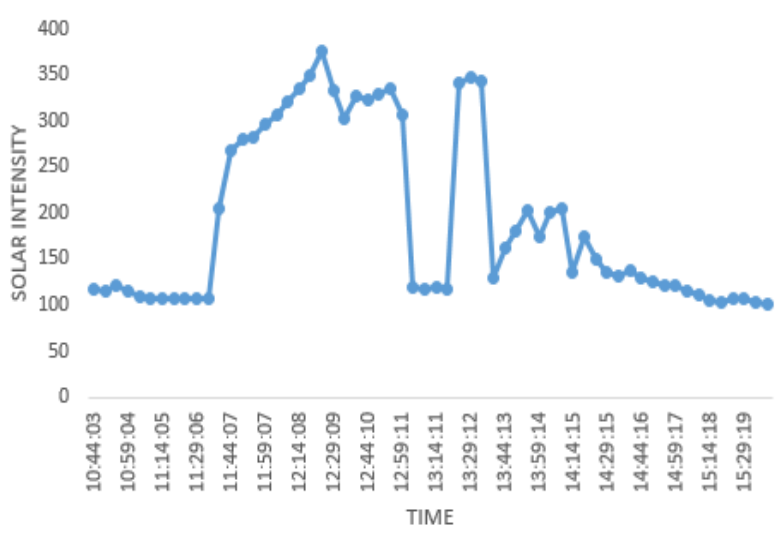

Fig. 2. Graph of solar intensity against time.

Solar intensity is shown against relative humidity in Fig. 3, and the greatest solar intensity observed was $320 \mathrm{~W} / \mathrm{m}^{2}$ at a relative humidity of 24 percent.

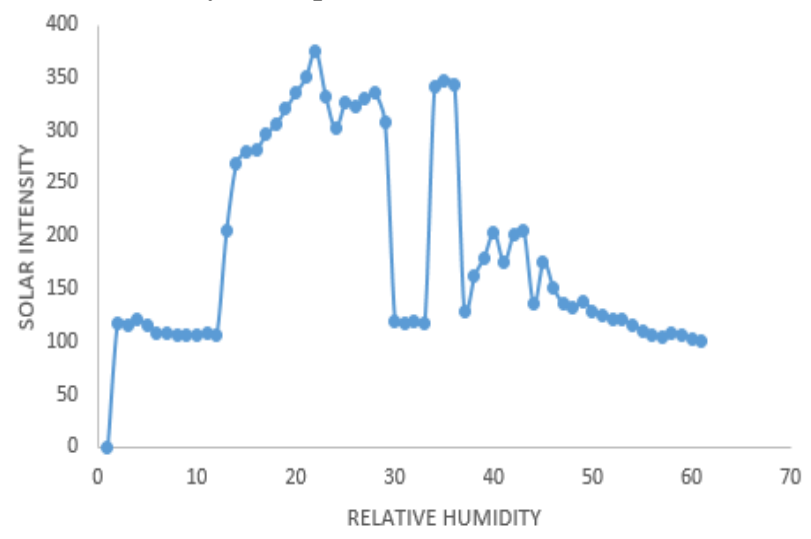

Fig. 3. Graph of solar intensity against relative humidity.
The fluctuation in the exergy output (Eexo) of the threereceiver tube to local time is depicted in Fig. 4. The maximum exergy output for an uncoated receiver tube was 1200 at 11:56 am; for a black receiver tube, it was 1000 at 11:56 am; and for a grey receiver tube, it was 900 at 1:26 pm.

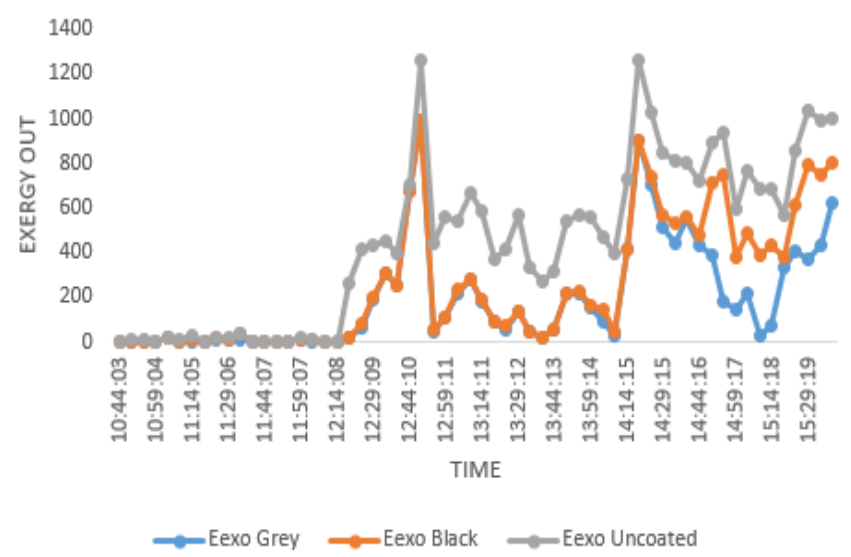

Fig. 4. Graph of Exergy out against Time for the three-receiver tubes.

The fluctuation in the exergy input (Eexi) of the threereceiver tubes to local time is depicted in Fig. 5. The maximum exergy in the uncoated receiver tube was 440 and was acquired at 11:11 am; the maximum exergy in the black receiver tube was 350 and was obtained at 11:26 am, and the maximum exergy in the grey receiver tube was 300 and was obtained at 11:26 am.

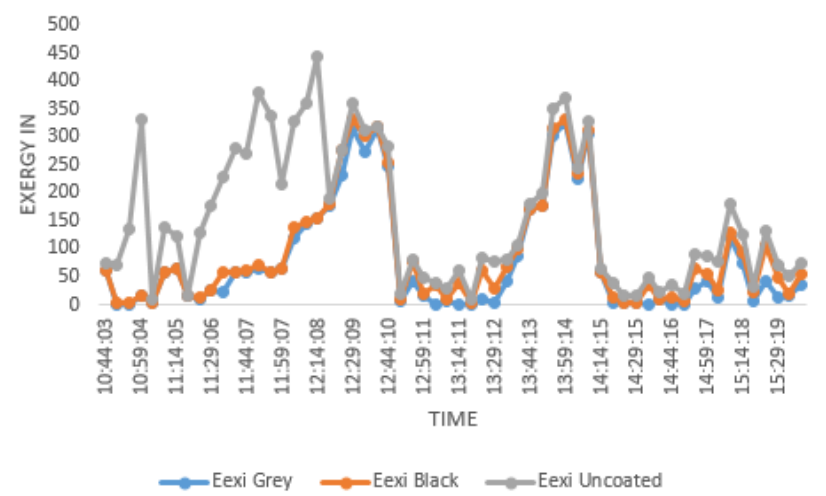

Fig. 5. Graph of Exergy in against time for the three-receiver tube.

Fig. 6 illustrates the variance in heat loss between the threereceiver tubes as a function of local time. Maximum heat loss was detected at 2500 for the uncoated receiver tube, 1800 for the grey coated receiver tube, and 2900 for the black-coated receiver tube, all of which were acquired at 11:26 am.

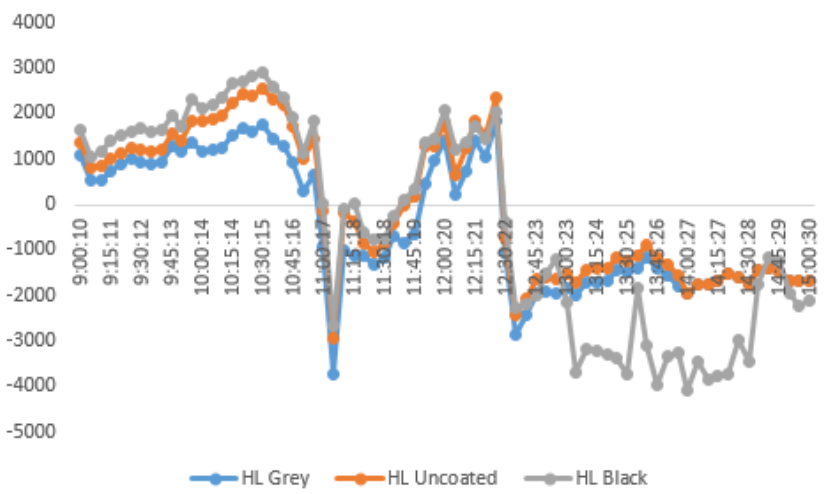

Fig. 6. Graph of heat loss against time for the three-receiver tubes. 
Fig. 7 illustrates the variance in inlet temperature for grey, uncoated, and black receiver tubes. When heat is extracted from the receiver tube, the maximum inlet temperature is achieved. The black receiver's maximum inlet temperature is $122{ }^{\circ} \mathrm{C}$. at 1.59 p.m.

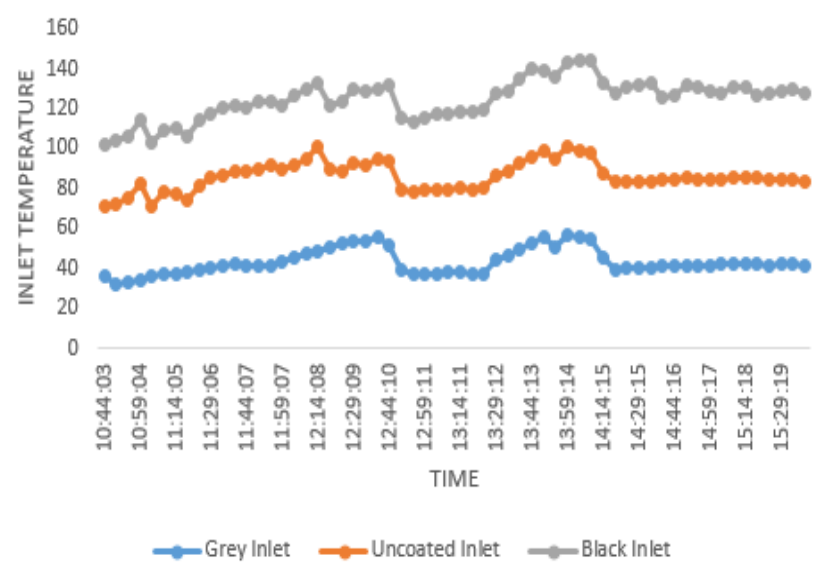

Fig. 7. Graph of Inlet Temperature against Time for the three-receiver tube.

Fig. 8 illustrates the variance in exit temperature for the three-receiver tubes. When heat is taken from the receiver tube, the maximum outlet temperature is reached. the black receiver's maximum outlet temperature is $162^{\circ} \mathrm{C}$, at $2.59 \mathrm{pm}$, it confirns the literature review that black body is perfect absorber.

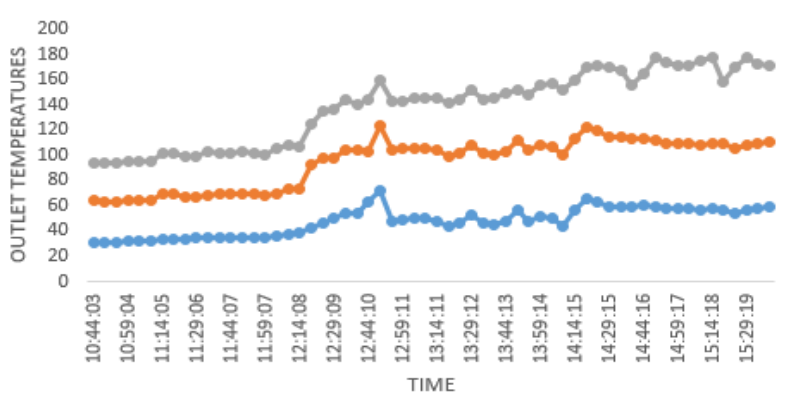

$\multimap$ Grey Outlet $\longrightarrow$ Uncoated Outlet $\longrightarrow$ Black outlet

Fig. 8. Graph of outlet temperature against time for the three-receiver tubes.

\section{CONCLUSIONS}

This study used a prototype parabolic trough solar concentrator with an aperture width of $1.2 \mathrm{~m}$, collector length of $2.1 \mathrm{~m}$, rim angle of $90^{\circ}$, and focal length of $30 \mathrm{~cm}$, which was tested in Ogbomoso environ $\left(8.1227^{\circ} \mathrm{N}, 4.2436^{\circ} \mathrm{E}\right)$. On the focal line of the parabolic trough, the concentrator has galvanized receiver tubes. A black, grey, and uncoated receiving tube was placed independently via the parabolic reflector's focal point. According to the findings, the heat transfer fluid's temperature and solar radiation have a significant impact on the thermal energetic performance. The exegetical efficiency is especially essential when the HTF inlet temperature is high. As a source of heat energy, the Parabolic Trough Solar Concentrator system has shown promising performance in this study. In addition to decreasing environmental issues, this concentrator allows for the sizing and performance evaluations of PTC solar fields.

\section{REFERENCES}

[1] García I L, Álvarez J L, Blanco D. Performance model for parabolic trough solar thermal power plants with thermal storage: Comparison to operating plant data. Solar Energy. 2011;85(10):2443-60.

[2] Fernández-García A., Zarza E., Valenzuela L., Pérez M. Parabolictrough solar collectors and their applications, Renewable Sustainable Energy Rev. 2010;14 (7):1695 - 1721.

[3] Kane M., Favrat D., Ziegler K., Allani Y. Thermoeconomic analysis of advanced solar-fossil combined power plants, Int. J. Thermodyn. 2010;3 (4):191-198

[4] You Y., Hu E. J. A medium-temperature solar thermal power system and its efficiency optimization, Appl. Therm. Eng. 2002;22 (4):357364.

[5] Singh N., Kaushik S., Misra R. Exergetic analysis of a solar thermal power system, Renewable Energy, 2000;19 (1):135-143.

[6] Baghernejad A., Yaghoubi M. Exergy analysis of an integrated solar combined cycle system, Renewable Energy, 2010;35(10):2157-2164.

[7] Reddy V.S., Kaushik S., Tyagi S. Exergetic analysis and performance evaluation of parabolic trough concentrating solar thermal power plant, Energy, 2012;39 (1):258-273.

[8] Zhai H., Dai Y., Wu J. Wang, R. Energy and exergy analyses on a novel hybrid solar heating, cooling and power generation system for remote areas, Appl. Energy, 2009;86 (9):1395-1404.

[9] Nafey A., Sharaf M. Combined solar organic Rankine cycle with reverse osmosis desalination process: energy, exergy, and cost evaluations, Renewable Energy, 2010; 35 (11):2571-2580.

[10] Sharafa M., Nafeya A., García-Rodríguez L. Exergy and thermoeconomic analyses of a combined solar organic cycle with multi effect distillation (MED) desalination process, Desalination, 2011;272 (13):135-147.

[11] Yahi F, Belhamel M., Berdja A M, Ouali M, Tetbirt M, Mokrane M, and Djebiret M. A. Modelling and Exergetic Analysis of a Parabolic Trough Solar Collector, IOP Conf. Series: Earth and Environmental Science, 2020;464: 1-7.

[12] Bharti A, Dixit A. and Paul B. Experimental analysis of a solar parabolic trough collector, International Journal of Mechanical Engineering and Technology (IJMET), 2018;9(6):102-112.

[13] Itabiyi O. E., Sangotayo E. O., Lateef A. K., \& Aminu I. F. Experimental Analysis of the Parabolic Trough Solar Concentrator Water Heater. European International Journal of Science and Technology, 2021;10(7): 1-12.

[14] Sangotayo E. O., Waheed M. A., Bolaji B.O. Thermal Evaluation of a Parabolic Trough Solar Concentrator Using Three Different Receivers, 2019 Journal of Energy Technologies and Policy, Vol.9, No.5, pp 1828.

[15] Sangotayo E. O. and Peter B. A. Comparative Assessment of the Effect of Thermo-Physical Properties on the Performance of Parabolic Trough Solar Collector, Journal of Applied Sciences, Information, and Computing, 2020;1(1): 9-19.

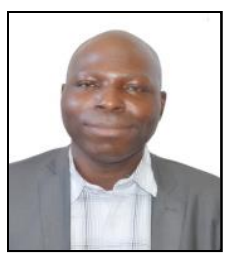

Emmanuel O. Sangotayo is a Senior Lecturer at the Ladoke Akintola University of Technology in Ogbomoso, Department of Mechanical Engineering. $\mathrm{He}$ is a COREN-registered engineer and a member of several professional organizations, including the NSE, NIMechE, ASME, and IEEE. His academic credentials include a B.Tech., M.Tech., and Ph.D. in Mechanical Engineering. His areas of research interest are thermofluids/energy studies, heat transfer, numerical computation and Mechanical Engineering

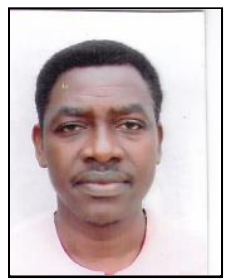

Taiye Adeyemo is a technologist at the Ladoke Akintola University of Technology in Ogbomoso, Department of Mechanical Engineering. He is a registered engineer, COREN, and a member of several professional organizations, including the NSE and the NIMechE. His academic background includes a Bachelor of Technology in Mechanical Engineering. The key areas of his research interests are Mechanical Engineering and Instrumentation

Goodness Temitayo Opatola is a research student at the Ladoke Akintola University of Technology in Ogbomoso, Department of Mechanical Engineering. Student member of NSE and NIMechE. His academic credential is Bachelor of Technology in Mechanical Engineering. Mechanical Engineering and Instrumentation are areas of his research interest. 
Azeez Abdulraheem is a research student at the Ladoke Akintola University of Technology in Ogbomoso, Department of Mechanical Engineering. Student member of NSE and NIMechE. His academic credential is a Bachelor of Technology in Mechanical Engineering. Mechanical Engineering and Instrumentation are areas of his research interest. 